\title{
EXCISION OF THE PROXIMAL END OF THE FEMUR FOR HIP STIFFNESS IN MYELOMENINGOCELE
}

\author{
LEE J. TAYLOR \\ From Queen Mary's Hospital for Children, Carshalton
}

\begin{abstract}
Operation on the hips of patients with myelomeningocele is often followed by stifiness or ankylosis. Excision of the upper end of the femur for this condition frequently fails because of extensive new bone formation.

Twelve excisions in eight patients are reported. Six of these patients had recently had spinal fusion operations; the consequent loss of ability to compensate for hip stifiness by spinal flexion had made sitting difficult or impossible. Excision or even re-excision of the upper femur failed in most cases. Careful assessment of hip mobility before spinal operations in these patients is essential and osteotomy rather than excision of the upper femur is advised.
\end{abstract}

Exuberant callus formation following a fracture in a patient with myelomeningocele is well recognised. The relationship between this and the extensive new bone formation which may occur after excision of the proximal femur in these patients is unknown. There are, moreover, few reports in the English literature on the results of this procedure in patients with myelomeningocele.

In 1978 Henry reported the results of nine excisional arthroplasties of the hip in five patients with severe cerebral palsy; he obtained very good results in four patients, but had problems with new bone formation in one. Pilliard et al. (1984), reporting 17 excisions of the proximal femur 2 to $10 \mathrm{~cm}$ below the lesser trochanter in patients with cerebral palsy, found that ectopic new bone formation was common, but did not significantly restrict hip movement.

\section{PATIENTS AND METHODS}

From 1976 to 1982 at Queen Mary's Hospital for Children, eight patients, five boys and three girls, had operations for excision of the proximal end of the femur. Twelve hips were operated upon, nine of them for postoperative ankylosis. The average age at operation was 13 years 2 months (range 11 to 16 years). There had been 13 previous operations on 9 of the 12 hips (Table I). At the time of operation, six hips were completely ankylosed, four were very stiff with less than 10 movement and two hips were mobile. None of the patients was able to walk. Ten of the operations were performed to improve the sitting position of the patient; the other two, on mobile

L. J. Taylor, FRCS, Senior Orthopaedic Registrar

Central Middlesex Hospital, Acton Lane, London NW10 7NS. England.

(C) 1986 British Editorial Society of Bone and Joint Surgery $0301-620 \times / 86 / 1023 \$ 2.00$ hips, were part of an attempt to heal large trochanteric sores.

\begin{tabular}{|c|c|}
\hline Operation & Number \\
\hline Soft-tissue release & 1 \\
\hline Excision of superolateral bar of bone & 5 \\
\hline Open adductor tenotomy & 2 \\
\hline Varus derotation osteotomy & 4 \\
\hline Open reduction & 1 \\
\hline Total & 13 \\
\hline
\end{tabular}

Six of the eight children had recently had corrective spinal fusion to improve their sitting position. Posterior Harrington rods were inserted in two of these; in the other four these were combined with anterior Dwyer instrumentation. These patients had lost flexion of the spine and therefore the ability to compensate for their stiff hips; excision of the proximal end of the femur was done, on average, eight months after the spinal fusion.

Technique of operation. A lateral approach was used to expose the upper femur to below the lesser trochanter, and an extra-periosteal excision carried out. For 48 hours the limb was maintained in straight traction; physiotherapy was then started with the aim of maintaining enough hip movement to allow sitting and lying.

\section{RESULTS}

The patients were reviewed at an average of three years after operation (range six months to six years).

Hip mobility. Re-ankylosis had occurred in eight of the 12 hips; of the four which had retained a satisfactory 90 


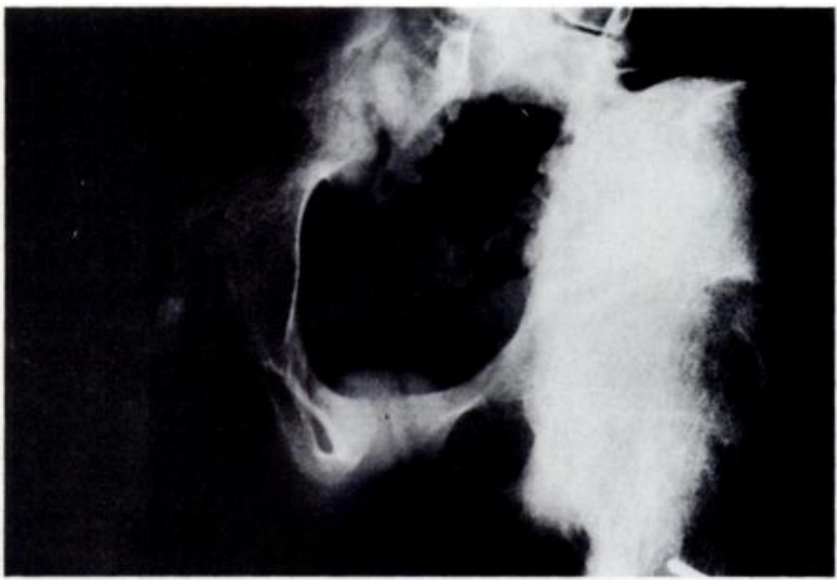

Fig. 1

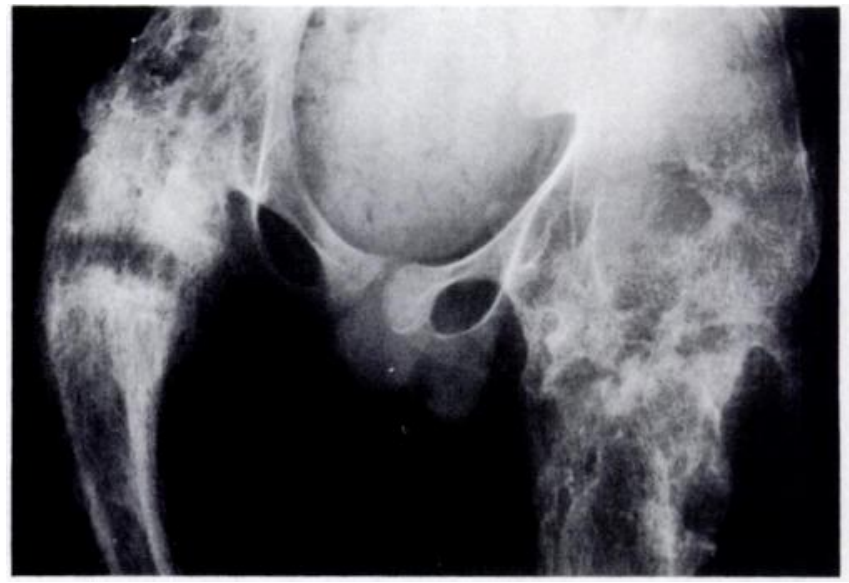

Fig. 2

Case 1. Figure I Radiograph showing ankylosis by extensive new bone formation after a previous hip operation. Figure 2 Recurrence of extensive bony ankylosis after excision of the upper end of both femora.

range of flexion, two were in a patient who died six months after operation from pneumonia, and the other two had had excision of mobile hips for sores and not for stiffness. Of the eight re-ankylosed hips, four subsequently had re-excision operations which were just as unsuccessful and one had a femoral osteotomy which successfully allowed him to sit comfortably with his stiff hip. Radiographs showed extensive new bone formation in 10 hips: no films were available for the patient who died six months after operation.

Wound healing. Wound healing was a frequent problem, and the two operations performed for trochanteric sores were unsuccessful. Only three of the 12 wounds healed by primary intention. Another three had healed by one month. three took four to six months and three remained unhealed after a year.

\section{Illustrative case histories}

Case 1. This patient with myelomeningocele had had an open reduction of the right hip at the age of two years and an osteotomy of the left hip at the age of five. Both hips ankylosed. When he was 14 years old he was no longer able to walk and could not sit comfortably in a wheelchair. The upper ends of both femora were excised, but within six months both were again very stiff and after two years both had completely re-ankylosed (Figs 1 and 2). A further excision operation was equally unsuccessful. Case 2. This patient had an open reduction of the right hip at the age of one year. Within six months the hip had ankylosed, with a solid superolateral bar of bone (Fig. 3). This was partially excised but soon reformed. At 12 years he had an operation for posterior spinal fusion, and six months later was unable to sit comfortably in a wheel-

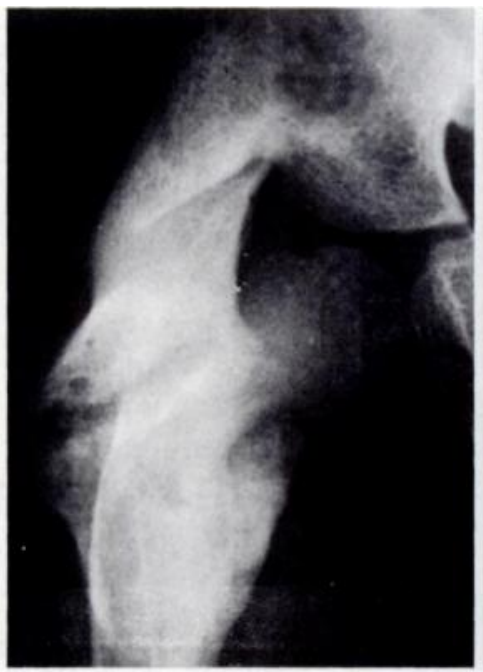

liig. 3

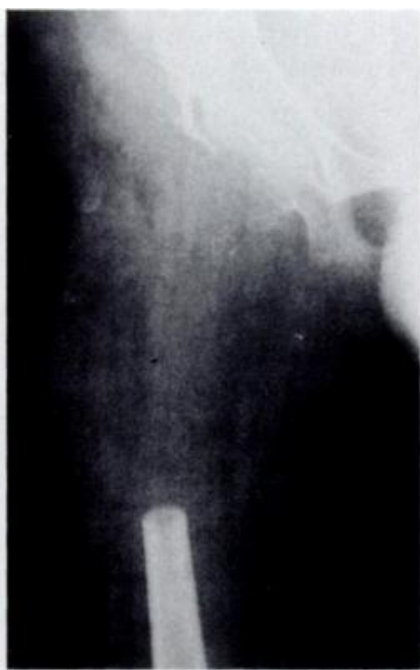

Fig. 4

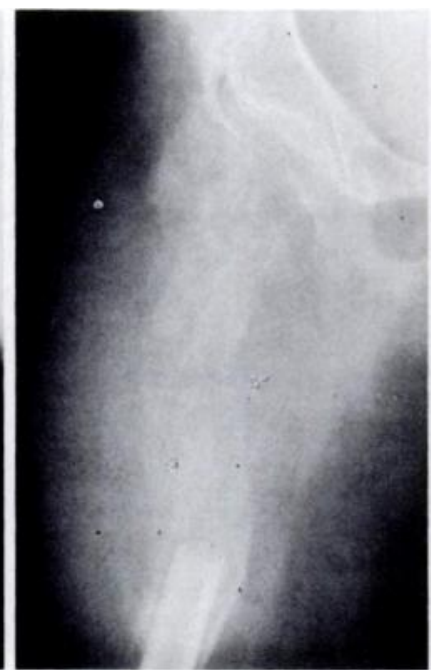

Fig. 5

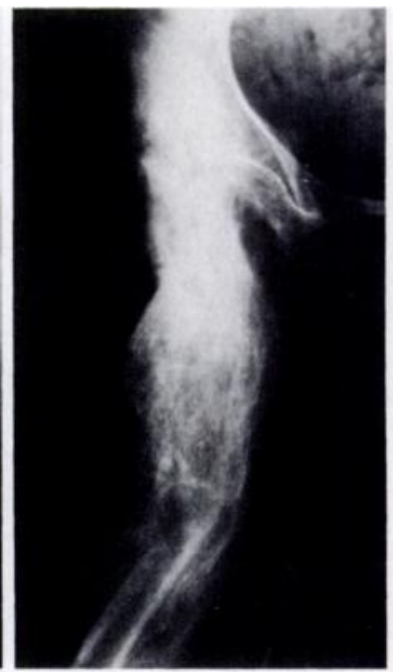

Fig. 6

Case 2. Figure 3 Hip ankylosed by a superolateral bar of bone; this was the commonest cause of hip stiffness in the series. Figure 4 -Postoperative radiograph showing radical excision of the upper end of the femur. Figure 5-After six weeks, new bone is already seen. Figure 6-After six months complete bony ankylosis has recurred. 
chair because of inability to compensate for his stiff hip by flexing his spine. He also developed a painful pseudarthrosis of the spinal fusion, which may have been related to efforts to compensate for hip stiffness. The upper end of his femur was excised (Fig. 4), but within six weeks extensive new bone was seen on the radiographs (Fig. 5), and after six months re-ankylosis had occurred (Fig. 6). A subsequent femoral osteotomy has allowed him to sit comfortably on his stiff hip.

\section{DISCUSSION}

Excision of the proximal end of the femur in the patients reported failed to improve hip mobility for more than a few weeks. In each case extensive new bone formation led to stiffness and recurrence of ankylosis. Re-excision was also unsuccessful.

Henry (personal communication, 1985) had only two cases of new bone formation after excision of nine hips in five patients with cerebral palsy and felt that this success could have been due to postoperative immobilisation of the hips at $90^{\circ}$ for three weeks. The patients in the series reported here were mobilised soon after operation. Pilliard et al. (1984) agree with Henry and also consider that closure of the capsule of the hip may help to limit new bone formation and prevent ankylosis.

The Carshalton experience of patients with myelomeningocele suggests that hip mobility must be carefully assessed before spinal surgery is undertaken in an attempt to improve sitting, since patients may lose the ability to compensate for hip stiffness by flexion of the spine and be made worse. Upper femoral osteotomy has been used with early success at Carshalton to provide a hip which is stiff but in a good position for sitting.

I would like to express my thanks to the photographic department at Redhill Hospital, to Mrs Linda Worsley for secretarial assistance and to Mr Geoffrey Walker for his considerable help and for allowing me to review his patients.

\section{REFERENCES}

Henry AN. Surgery for hip dislocation in severe cerebral palsy. SICOT XIV world congress: abstracts. Kyoto. Japan, 1978:36-7.

Pilliard D, Benoit S, Taussig G, Masse P. Resection of the upper end of the femur in children with spastic quadriplegia. J Bone Joint Surg $[B r]$ 1984;66-B: 142 . 